\title{
Emerging Economies Business Cycles: The Role of Commodity Terms of Trade News*
}

\author{
Nadav Ben Zeev ${ }^{\dagger} \quad$ Evi Pappa $a^{\ddagger} \quad$ Alejandro Vicondoa $\$$
}

July 17, 2017

\begin{abstract}
Recent empirical work has challenged the hypothesis that terms-of-trade shocks are an important source of cyclical fluctuations in emerging economies. We show that ignoring the news component in the terms-of-trade movements results in misleading conclusions about their importance as a source of cyclical fluctuations. Using a sample of Latin American countries, we identify news-augmented Commodity-terms-of-trade (CTOT) shocks by maximizing the forecast error variance share of the CTOT series at a finite future horizon. Our identification does not rely on zero impact restrictions typically used in the literature for recovering news shocks. Accounting for news almost doubles the contribution of CTOT to explain cyclical fluctuations: news-augmented CTOT shocks explain almost half of output variations in emerging economies.
\end{abstract}

JEL classification: E32, F41

Keywords: Commodity terms of trade, business cycles, news shocks, maximum forecast error variance, small open economy.

\footnotetext{
${ }^{*}$ We are grateful to Martin Uribe, two anonymous referees, and seminar participants at the Banco Central de la República Argentina, Bocconi University, EEA-ESEM 2016 Conference, European University Institute, GPEFM Alumni meeting 2015, LUISS Guido Carli, Universidad Carlos III de Madrid, University of Bonn, University of Surrey, and University of York for helpful comments and suggestions. A previous versions of this paper was circulated with the title: "Emerging Economies Business Cycles: The Role of Terms of Trade Revisited".

${ }^{\dagger}$ Ben-Gurion University of the Negev. Email: nadavbz@bgu.ac.il.

${ }^{\ddagger}$ European University Institute. Email: evi.pappa@eui.eu.

§Pontificia Universidad Católica de Chile. Email: alejandro.vicondoa@uc.cl.
} 


\section{Introduction}

Until recently it has been commonly accepted in the international macroeconomics literature that shocks to the terms of trade (henceforth, TOT) - price of exports relative to the price of imports were an important determinant of macroeconomic dynamics in most emerging market economies (henceforth, EMEs; see, e.g., Mendoza, 1995; Kose, 2002). In their latest article, however, SchmittGrohé and Uribe (2017) have challenged this traditional view by estimating annual country-specific SVARs for 38 poor and EMEs and showing that TOT shocks explain on average 10 percent of movements in aggregate activity.

The starting point of our analysis is that many TOT movements are anticipated. The increases in the TOT observed during the 2000s for many economies were largely due to rising commodity prices, driven by strong economic growth in countries such as China and India (Kilian and Hicks, 2013). To the extent that agents recognize the underlying causes of changes in the TOT, it is reasonable to assume that they are able to forecast these fluctuations and modify their current economic decisions accordingly. Hence, it is important to examine whether anticipated movements in the TOT matter for business cycle dynamics of small emerging countries.

This paper studies the macroeconomic effects of news shocks to the TOT. There has recently been a renewed interest in theories of expectation-driven business cycles, focusing in particular on the effects of news shocks: shocks which are realized and observed before they materialize. Beaudry and Portier (2006) were the first to provide empirical evidence in favor of this hypothesis in the context of structural VARs, by assuming that TFP news should affect stock prices but not TFP on impact. More recently, Barsky and Sims (2011) identify TFP news shocks by assuming that such shocks should maximize the forecast error variance of TFP movements in the medium run without affecting contemporaneously TFP. Our identification assumptions differ in one critical way from those in Beaudry and Portier (2006) and Barsky and Sims (2011). In our identification of TOT news shocks, we do not impose the orthogonality restriction that news to the TOT cannot affect the TOT contemporaneously. Since TOT typically relate to the future value of storable goods, an anticipated future change in the TOT may cause a current movement in this variable through movements in 
inventories (see, e.g., Pindyck, 2001; Roache and Erbil, 2010). ${ }^{1}$

Given the shortcomings of employing zero impact restrictions, we employ an alternative identification strategy for extracting news about TOT movements in the data. Our identification strategy relies on "medium-run" restrictions and builds on Uhlig (2003), Barsky and Sims (2011), and mainly on Kurmann and Sims (2017). In particular, our benchmark specification consists of country-specific quarterly VARs for Argentina, Brazil, Chile, Colombia, and Peru. ${ }^{2}$ Following Shousha (2016) and Schmitt-Grohé and Uribe (2017), our VAR model consists of foreign exogenous and domestic endogenous variables. The exogenous variables are the commodity based TOT index (henceforth, CTOT), computed as the real price index of the country commodity export bundle, and the U.S. corporate bond (Baa) spread, which we use as an indicator for global financial conditions for emerging economies (Akinci, 2013). The domestic endogenous variables include: output, consumption, investment, the trade balance, the real exchange rate, and a measure of country-spreads, proxied by the JP Morgan EMBI Global Index. We identify CTOT shocks as the disturbances that best explain future movements in the CTOT at a horizon of five quarters and that can be correlated to current CTOT movements. In particular, following the evidence presented by Chen, Rogoff, and Rossi (2010) and Fernández, González, and Rodríguez (2015), we exploit variations in domestic macroeconomic variables, exchange rates, and country spreads together with the exogeneity of CTOT to identify news about CTOT. Lifting the orthogonality condition comes at a cost since we are able to identify only a combination of shocks that maximize the forecast error variance of CTOT and it includes both unexpected shocks, as well as the anticipated component in the CTOT movements. For this reason, we call our extracted shocks "news-augmented CTOT shocks".

News-augmented CTOT shocks induce significant and persistent increases in output, consumption, and investment. The Trade Balance also increases significantly for several periods after the shock and spreads decrease significantly. This fact confirms the findings of Fernández, González,

\footnotetext{
${ }^{1}$ Following the approach of Beaudry and Portier (2006), we could use fluctuations in commodity future prices to extract news shocks about the TOT. However, that would be problematic for two reasons. First, we could not have used the zero restriction that future changes are orthogonal to current movements in the TOT. Second, since time varying risk premia is a relevant determinant of commodity future prices (see, e.g Kaminsky, 1990; Baumeister and Kilian, 2016), extracting information for fundamental movements from those series would not have been straightforward.

${ }^{2}$ Commodities account for at least 30 percent of total exports for this set of Latin American countries. Fernández, González, and Rodríguez (2015) and Shousha (2016) use a similar set of countries in their analysis and our results can be easily comparable to theirs.
} 
and Rodríguez (2015) and Shousha (2016), who suggest that unexpected commodity price shocks are important in Latin American countries because they reduce country spreads causing larger expansions that would otherwise occur. Finally, news-augmented CTOT shocks appreciate the real exchange rate with a lag.

News-augmented CTOT shocks explain, on average, 49 percent of cyclical fluctuations, while traditional shocks to the CTOT recovered using the standard Cholesky decomposition, as in SchmittGrohé and Uribe (2017), explain on average half of those fluctuations. ${ }^{3}$ Other studies have analyzed the role of commodity prices, as a source of cyclical fluctuations (see, e.g., Fernández, González, and Rodríguez, 2015; Shousha, 2016; Fernández, Schmitt-Grohé, and Uribe, 2017). All these works find that world shocks transmitted through commodity prices explain around one third of business cycle fluctuations, but they have only considered the role of unanticipated shocks. In this paper, we show that accounting for anticipation restores the importance of the terms of trade as a source of cyclical fluctuations in emerging economies. Moreover, our conclusions do not hinge on the specific measure of terms of trade (i.e. commodity based or export and import unit values) and are robust to various sensitivity analysis. Finally, our results are also comparable to the ones of Arezki, Ramey, and Sheng (2017) who study the macroeconomic effects of news about oil discoveries in a small open economy. However, we consider expected changes in prices of a vast set of commodities that may be due to external shocks instead of expected changes in the domestic stock of oil.

The remainder of the paper is organized as follows. Section 2 describes the econometric framework. Section 3 presents the benchmark empirical results. Section 4 reports the results from additional robustness exercises and extensions. Section 5 concludes.

\section{Econometric Strategy}

Our identification strategy relies on the Maximum Forecast Error Variance (MFEV) identification approach put forward by Uhlig (2003) and later extended by Barsky and Sims (2011) and Kurmann

\footnotetext{
${ }^{3}$ Schmitt-Grohé and Uribe (2017) find that TOT surprise shocks explain on average 10 percent of output fluctuations in EMEs. However, the Forecast Error Variance (FEV) increases up to 19 percent if we consider only Argentina, Brazil, Colombia, and Peru, which are the countries considered in our sample, and to 27 percent if we consider all the Latin American countries of their sample.
} 
and Sims (2017). To identify the news-augmented TOT shocks, we need to estimate first a VAR that includes the main transmission channels of TOT shocks. As explained in Barsky and Sims (2011), an appealing way to identify news shocks to a fundamental, which is driven by an unanticipated shock and a news shock, is to estimate a reduced-form multivariate VAR where all variables, including the fundamental itself, are regressed on their own lags, as well as the other variables' lags. Then, the resulting VAR innovations are used to search for the structural shock that satisfies the medium run restrictions. Following Kurmann and Sims (2017), we (a) extract a news-augmented CTOT shock that accounts for the maximum FEV share of CTOT at one truncation horizon, $\mathrm{H}=5$; (b) do not impose that the news shock is orthogonal with respect to the innovation in CTOT. ${ }^{4}$ According to Chinn and Coibion (2014) and Husain and Bowman (2004), the optimal horizon for predicting commodity prices varies between one and two years. We choose 5 quarters for the anticipation horizon as an average of those values and also, as we show in Section 4, this is the anticipation horizon for which the linear combination of shocks maximizes the FEV of CTOT two years ahead.

Following Shousha (2016); Fernández, Schmitt-Grohé, and Uribe (2017) and Schmitt-Grohé and Uribe (2017), our baseline VAR model consists of foreign (exogenous) and domestic variables. The foreign variables include a country-specific CTOT series and the U.S. corporate bond (Baa) spread. We define CTOT as the real price index of the country commodity export bundle, where the weights are computed as a simple average of the export share of each good for the period 1994-2013 (Shousha, 2016). The Baa corporate spread, which is defined as the difference between Moody's Baa corporate bond yield and the Federal Funds rate and constitutes a relevant indicator of global financial conditions for emerging economies (Akinci, 2013), helps to control for another channel that is important for the transmission of world shocks to open economies. The domestic variables consist of six domestic macroeconomic indicators: output, consumption, investment, the trade balance, the real exchange rate, and a measure of country-spreads. We include country spreads, proxied by the JP Morgan EMBI Global Index, in the benchmark model for several reasons. First, CTOT news shocks generate foresight about changes in future fundamentals and lead to an undeniable

\footnotetext{
${ }^{4}$ Barsky and Sims (2011) extract news about the fundamental instead by maximizing the sum of the FEV shares from impact period onwards and employ an orthogonality condition for the extracted news series relative to current movements in the fundamental.
} 
missing state variable problem and, hence, non-invertible VAR representations. As is shown in Sims (2012), conditioning on more forward looking variables ameliorates or eliminates invertibility problems altogether. As a result, including country spreads in the VAR is essential for addressing the missing information problem. Second, according to Uribe and Yue (2006), country spreads respond endogenously to business cycle conditions in EMEs and might be affected by external and anticipated shocks, such as the shocks in the CTOT. Finally, following Chen, Rogoff, and Rossi (2010) and Fernández, González, and Rodríguez (2015), the country spread and the exchange rates may contain useful information to identify expected movements in the CTOT. Details of all the series used are described in Appendix A.

The news shocks literature typically assumes that technology is driven by two exogenous components, one related to news about expected future changes in fundamentals and the other capturing unanticipated, or current shocks (see, e.g., Beaudry and Portier, 2006). The news shocks are then identified by exploiting the contemporaneous dynamics of macroeconomic and financial variables and by imposing that they affect technology only with a delay. Thus, the main identification assumption is that technology evolves according to an exogenous process, which is independent of the rest of the variables. In order to identify news about CTOT, we also assume that the CTOT are exogenous for the small open economy, so we can use domestic macroeconomic and financial variables to identify expected fluctuations in this variable. Following the evidence presented by Chen, Rogoff, and Rossi (2010) and Fernández, González, and Rodríguez (2015), we allow variations in domestic macroeconomic variables, such as exchange rates and country spreads, to feedback on the identification of news about CTOT. We depart from the existing literature for identifying exogenous news shocks by not imposing the zero impact restriction. The latter restriction is not appealing for the identification of commodity prices shocks since their storability implies that news in commodity prices can be hedged through movements in inventories and, as a result, will very often result to movements in commodity prices contemporaneously. ${ }^{5}$ Thus, it is very likely that news about future CTOT movements induce changes in CTOT today. ${ }^{6}$

\footnotetext{
${ }^{5}$ For a discussion of the inventory channel see Pindyck (2001) and Roache and Erbil (2010).

${ }^{6}$ Moreover, Kurmann and Sims (2017) show that, even if CTOT react to news shocks only with a delay, the zero impact restriction may still be violated in the data if the measure of CTOT is confounded by measurement error.
} 
Specifically, let the VAR in the observables be given by:

$$
y_{t}=F_{1} y_{t-1}+F_{2} y_{t-2}+\ldots+F_{p} y_{t-p}+F_{c}+e_{t}
$$

where $y_{t}$ represents the vector of observables, where the first two variables are the CTOT series and the Baa corporate spread, $F_{i}$ are $8 \times 8$ matrices, $p$ denotes the number of lags, $F_{c}$ is a $8 \times 1$ vector of constants, and $e_{t}$ is the $8 \times 1$ vector of reduced-form innovations with variance-covariance matrix $\Sigma$. The reduced form moving average representation in the levels of the observables is:

$$
y_{t}=B(L) e_{t}
$$

where $B(L)$ is a $8 \times 8$ matrix polynomial in the lag operator, $L$, of moving average coefficients and $e_{t}$ is a $8 \times 1$ vector of reduced-form innovations. Then, the $h$ step ahead forecast error is:

$$
y_{t+h}-\mathbb{E}_{t} y_{t+h}=\sum_{\tau=0}^{h} B_{\tau} e_{t+h-\tau},
$$

where $B_{\tau}$ is the matrix of moving average coefficients at horizon $\tau$. The contribution to the forecast error variance of variable $i$ attributable to shock $j$ at horizon $h$ is then given by:

$$
\Omega_{i, j}=\sum_{\tau=0}^{h} B_{i, \tau} \gamma \gamma^{\prime} B_{i, \tau}^{\prime},
$$

where $\gamma$ is a $8 x 1$ vector corresponding to the $j$ th column of a possible orthogonalization, and $B_{i, \tau}$ represents the $i$ th row of the matrix of moving average coefficients at horizon $\tau$. We index the CTOT shock as 1 in the vector of structural shocks. The identification of news-augmented CTOT shocks requires finding the $\gamma$ which accounts for the maximum FEV share at one horizon $H$ (the truncation horizon), and is allowed to affect CTOT movements on impact. Formally, this identification strategy requires solving the following optimization problem

$$
\begin{gathered}
\gamma^{*}=\max \Omega_{1,1}(H) \\
\text { subject to } \gamma^{\prime} \gamma=1
\end{gathered}
$$


The restriction imposes on $\gamma$ to have unit length, ensuring that $\gamma$ is a column vector belonging to an orthonormal matrix. This normalization implies that the identified shocks have unit variance, but we do not restrict it to have a zero in its first entry, meaning that we allow the news-augmented CTOT shock to impact CTOT immediately.

We follow the conventional Bayesian approach to estimation and inference by assuming a diffuse normal-inverse Wishart prior distribution for the reduced-form VAR parameters. Specifically, we take 1000 draws from the posterior distribution of reduced form VAR parameters $p(F, \Sigma \mid$ data), where for each draw we solve optimization problem (5); we then use the resulting optimizing $\gamma$ vector to compute impulse responses to the identified shock. ${ }^{7}$ This procedure generates 1000 sets of impulse responses which comprise the posterior distribution of impulse responses to our identified shock. Our benchmark choices for the number of lags and truncation horizon are $\mathrm{p}=2$ and $\mathrm{H}=5$, respectively. ${ }^{8}$

\section{Empirical Evidence}

\subsection{Data}

We estimate five country-specific VARs. Data are quarterly and samples are as follows: Argentina 1994:Q1-2013:Q3, Brazil 1995:Q1-2014:Q3, Chile 1999:Q2-2014:Q3, Colombia 1997:Q1-2014:Q3, and Peru 1997:Q1-2014:Q3. Appendix A contains a detailed description of the data. Following Shousha (2016), we focus on Latin American commodity exporters, defined as countries where exports of commodities account for more than 30 percent of total exports, but later draw comparisons with samples with more emerging countries, when relevant. However, we found that analyzing all set of Latin American and Asian countries together in the benchmark regression, as Schmitt-Grohé and Uribe (2017) do, was not a good idea for several reasons: a) the two regions are different both in CTOT performance and in terms of output dynamics, and b) while in Latin America there is a lack of potential supply conditions to determine the CTOT by smaller economies, in Asia some economies have become in a few years very influential in international markets.

\footnotetext{
${ }^{7}$ Note that $\mathrm{F}$ here represents the stacked $(8 \times(p+1)) \times 8$ reduced form VAR coefficient matrix, i.e., $F=\left[F_{1}, \ldots, F_{p}, F_{c}\right]$.

${ }^{8}$ Results are also robust to different VAR lag specifications. These results are available from the authors upon request.
} 


\subsection{Impulse Responses and Forecast Error Variance Decomposition}

Figure 1 shows the estimated cross country average impulse responses of all variables to a one standard deviation news-augmented CTOT shock from the benchmark VAR. The bands in the figures are one standard error bands, where the standard error is the one corresponding to the standard error of the average estimate obtained from using the variances of the individual countries impulse responses. All responses should be interpreted as the typical responses of a Latin American country to the combination of anticipated and unanticipated exogenous increase in the CTOT. We present the individual responses in the Online Appendix.

News-augmented CTOT shocks increase CTOT on impact and persistently and the CTOT response reaches its peak in the fourth quarter. The shock induces an immediate increase in output and a delayed positive response of consumption and investment. These responses are reflected in a contemporaneous improvement in the trade balance. In response to the news-augmented shock in the CTOT, the country spread falls significantly on impact and persistently. This response confirms the findings in Fernández, González, and Rodríguez (2015) and Shousha (2016), who suggest that commodity price shocks are important in Latin American countries because they reduce country spreads causing larger expansions that would otherwise occur. The real exchange rate sluggishly appreciates. Turning to the variance decomposition in Table 1, we observe that news-augmented CTOT shocks explain on average 49 percent of output fluctuations and 31 percent of country spreads fluctuations.

News-augmented CTOT shocks are an important source of business cycle fluctuations for all the countries in the sample. Table 1 displays their contribution in explaining the FEV of the macroeconomic variables included in the VAR. Although the relevance is similar across countries, news-augmented CTOT shocks are particularly important for Colombia and slightly less

for Argentina. These differences in FEV may be associated with the different goods exported by each country, the structure of the economy, and also to the share of commodity exports over total exports. This can also be seen by the differences in the correlation of the shocks. On average the correlation of news-augmented CTOT shocks equals 0.24 . Shocks are more correlated between Argentina and Brazil (0.48), and Chile and Peru (0.38) that are both agricultural and metal exporters, 
respectively, while the correlation of news-augmented CTOT shocks between Peru and Brazil is smaller, since the latter economy mostly exports agricultural products. According to the findings in Fernández, González, and Rodríguez (2015), a significant fraction of the evolution of the CTOT indices is explained by a common factor. The high estimated correlation of the news-augmented CTOT shocks supports their conclusion.

\subsection{Comparison with Standard Cholesky CTOT Shocks}

In this section, we assess how the news-augmented CTOT shocks compare to the standard CTOT shocks discussed in the literature. Typically, CTOT shocks are identified using a Cholesky decomposition in SVAR systems similar to the one of our baseline specification. Figure 2 displays the impulse responses of our baseline VAR when we identify CTOT shocks using the Cholesky decomposition and Table 2 reports the FEVDs for individual countries.

Figure 2 is comparable with the findings of Schmitt-Grohé and Uribe (2017). Our responses are not qualitatively very different from theirs besides the fact that the sample, the terms of trade index, and the frequency of the data are different. The CTOT shocks induce an appreciation of the real exchange rate and an improvement on impact of the trade balance. Contrary to their findings, the initial consumption, and investment, responses to the CTOT positive disturbance are not significant and they increase with a lag. Turning to the variance decompositions (see Table 2), we also confirm the Schmitt-Grohé and Uribe (2017) findings. CTOT shocks explain over a two-year horizon on average 13 percent-23 percent of fluctuations in output, consumption, investment, and the trade

balance. For Argentina and Colombia unexpected CTOT shocks explain almost 9 percent and 37 percent, respectively, of output fluctuations, while for the other countries, those numbers are comparable. Moreover, Cholesky CTOT shocks explain 19 percent of spread fluctuations. Overall, these results are very similar both qualitatively and quantitatively to the findings of Shousha (2016), who uses a very similar sample and terms of trade index to ours.

There is a noticeable similarity between the responses of the Cholesky CTOT shocks and the news-augmented CTOT shocks we extract using our methodology. Indeed, the correlation between the two shocks is on average 72 percent. However, when we compute the 68 percent credible sets 
for the FEVD in the two models reported in parenthesis in Tables 1 and 2, we see that, with the exception of the dynamics of the exchange rate, the model that accounts for news shocks in the CTOT series explains a significantly higher variability in macro variables relative to the standard Cholesky identification used in the existing literature for recovering terms of trade shocks.

\section{Alternative Specifications}

In this section, we consider alternative VAR specifications for our empirical exercise. The impulse responses of all the exercises performed in this section are included in the Online Appendix. Here, for ease of exposition, we only present the share of variance explained by the news-augmented CTOT shocks in every exercise on average in Table 3.

\subsection{Truncation Horizon}

Taking both the results of Chinn and Coibion (2014) and Husain and Bowman (2004) and the truncation horizon for which news-augmented CTOT shocks maximize the two year FEVD of CTOT into account, in the benchmark VAR we use 5 quarters for the truncation horizon to recover our news-augmented CTOT news shocks. Yet, the same authors suggest that the optimal horizon for predicting commodity prices varies between one and two years. The second and third rows of Table 3 report results when we vary the truncation horizon to 3 quarters and 8 quarters. Changing the truncation horizon does not change results regarding the importance of the identified shocks in explaining aggregate fluctuations in emerging countries. Moreover, the IRFs, which are included in the online appendix, do not change significantly.

\subsection{Government Spending}

Since sovereign spreads are negatively affected by news-augmented CTOT shocks, the government reaction to such shocks might be key for shaping business cycle fluctuations. Ilzetzki and Vegh (2008) show that fiscal policy is procyclical in developing countries. The problem of procyclicality seems to be more acute in commodity rich nations since commodity related revenues can be a large proportion of total government revenues (see, e.g., Sinnott, 2009). Céspedes and Velasco (2014) 
study the behavior of fiscal variables across the commodity cycle and show that there is a negative relation between the fiscal balance and the behavior of commodity prices.

In this exercise, we introduce government expenditure as an additional endogenous variable in our benchmark SVAR. The fourth row of Table 3 presents the share of variance explained by the identified CTOT shocks when we control for movements in government spending in our analysis. The share of macroeconomic fluctuations explained by news-augmented CTOT shocks remains unchanged. In line with Ilzetzki and Vegh (2008), we learn from this exercise that government reacts positively and persistently to the identified shock and such shocks explain 18 percent of government spending variability. ${ }^{9}$

\subsection{Alternative Measures of World Interest Rates}

Anticipated shocks that affect future commodity prices may also induce movements in the world real interest rate, which is the relative price of goods at different periods. Thus, the interest rate may be crucial for the transmission of news-augmented CTOT shocks. In our baseline specification, following Schmitt-Grohé and Uribe (2017) and Fernández, Schmitt-Grohé, and Uribe (2017), we include the U.S. corporate bond spread, which is a key financial variable for emerging economies (Akinci, 2013). However, including this variable does not affect significantly our results (see the seventh row of Table 3) providing evidence against the idea of financialization of commodity markets, in line with the findings of Fernández, Schmitt-Grohé, and Uribe (2017). Following Shousha (2016) and Fernández, Schmitt-Grohé, and Uribe (2017), we also consider specifications where we include the real three-month U.S. Treasury bill rate and the Federal Funds rate instead of the U.S. corporate spread. ${ }^{10}$ Results of these exercises appear in the fifth and sixth row of Table 3, respectively. Unsurprisingly, changing the measure for the world interest rate does not modify our baseline results. When we proxy the world interest rate with the FFR and the real Tbill rate, results seem almost identical to the baseline specification apart from slight differences in the predictive power of the shock in explaining exchange rate and spread fluctuations. Overall, the role of news-

\footnotetext{
${ }^{9}$ See the Online appendix for the impulse responses.

${ }^{10}$ The real Till rate is computed at monthly frequency as the difference between the nominal three months Tbill rate and the annualized U.S. CPI inflation over the last year. Then, we aggregate it to quarterly frequency by computing the average.
} 
augmented CTOT shocks to explain cyclical fluctuations in Latin American countries is far from negligible (i.e. they explain around 50 percent of output variations), as opposed to 25 percent in the results of Shousha (2016).

\subsection{Financial Variables}

Previous works in the news literature use financial variables to identify anticipated fluctuations in macroeconomic variables. As we mentioned before, commodity futures may be subject to time varying risk premia and may bias the identification of the shocks (see, e.g., Kaminsky, 1990; Baumeister and Kilian, 2016). However, we think that it is important to assess the response of these variables to the identified shocks and to see if they affect our main conclusions. Thus, in this subsection, we extend our baseline specification to include country specific stock price indexes and CTOT future prices. The eighth and ninth rows of Table 3 display the FEV for both specifications. Including either variable does not change the relevance of news-augmented CTOT shocks to explain business cycles dynamics. As expected, news-augmented CTOT shocks are a relevant driver of fluctuations in CTOT futures (70 percent) and also of stock prices (39 percent).

\subsection{TOT Shocks}

In their conclusions, Schmitt-Grohé and Uribe (2017) suggest that an improvement in their empirical model could stem from entertaining the hypothesis that commodity prices are a better measure of the TOT than aggregate indices of export and import unit values, especially for countries whose exports or imports are concentrated in a small number of commodities. In accordance with the existing literature (see, e.g., Fernández, González, and Rodríguez, 2015; Shousha, 2016), we estimate our baseline VAR using the commodity-based TOT index. In order to investigate whether our conclusions are sensitive to the measure of TOT used in the empirical model, we have re-estimated our benchmark model substituting commodity-based TOT with the TOT index. Results from this exercise appear in the tenth row of Table 3. Using the TOT series in our baseline regressions, as suggested by Schmitt-Grohé and Uribe (2017), reduces indeed the importance of news-augmented TOT shocks to explain cyclical fluctuations, but does not change the fact that these shocks explain a 
significant part of fluctuations in emerging countries. News-augmented TOT shocks explain on average 32 percent of output fluctuations.

\subsection{The Schmitt-Grohé and Uribe (2017) Specification}

In the previous sensitivity analysis we have compared our results with the ones of Schmitt-Grohé and Uribe (2017) by changing one assumption at the time. Here we continue by analyzing the empirical specification used in Schmitt-Grohé and Uribe (2017), in order to compare directly our empirical results with theirs and to show that differences are not due to the different sample, frequency, or variables included in the VAR. In this exercise, we use exactly the same sample and variables as Schmitt-Grohé and Uribe (2017). That is, we estimate country by country VARs using annual data for 38 emerging and poor countries that include the TOT, U.S. corporate spread, real output, private consumption, investment, the real exchange rate, and the ratio of trade balance to GDP. ${ }^{11}$ In the eleventh row of Table 3 we present the share of variance explained by the identified TOT shocks in this exercise. News-augmented TOT shocks explain almost triple of the variance of output relative to the Cholesky TOT shocks in Schmitt-Grohé and Uribe (2017). ${ }^{12}$ When we repeat their exercise but using only the sample of Latin American countries that overlaps with our baseline sample, the contribution of news-augmented TOT shocks to explain output fluctuations increases to 28 percent. ${ }^{13}$

\subsection{The Exchange Rate Regime}

Fluctuations of the nominal exchange rate have important effects on relative prices. Therefore, an interesting and important ingredient missing in the analysis so far is the exchange rate regime. Broda (2004) shows that countries with flexible exchange rate regimes have faster adjustment of

\footnotetext{
${ }^{11}$ The Schmitt-Grohé and Uribe (2017) data set is available online and includes the following countries: Algeria, Argentina, Bolivia, Botswana, Brazil, Burundi, Cameroon, Central African Republic, Colombia, Congo Dem. Rep., Costa Rica, Cote d'Ivoire, Dominican Republic, Egypt Arab Rep., El Salvador, Ghana, Guatemala, Honduras, India, Indonesia, Jordan, Kenya, Korea Rep., Madagascar, Malaysia, Mauritius, Mexico, Morocco, Pakistan, Paraguay, Peru, Philippines, Senegal, South Africa, Sudan, Thailand, Turkey, and Uruguay for the period 1980 to 2011.

${ }^{12}$ Schmitt-Grohé and Uribe (2017) show that TOT shocks explain 7 percent of GDP fluctuations in the specification that includes the Baa corporate spread.

${ }^{13}$ This set of countries consists of: Argentina, Brazil, Colombia, and Peru. Chile is not considered in the sample of Schmitt-Grohé and Uribe (2017). For this subsample, the FEV of output explained by Cholesky TOT shocks is 19 percent.
} 
relative prices and, thus, smoother real responses than the ones with fixed regimes, supporting the hypothesis of Friedman (1953). Since the selection of countries in our benchmark regressions is not sufficiently large to consider heterogeneity of exchange rate regimes across countries and across time, in this section we first extend our analysis to 10 emerging economies for which quarterly data are available. ${ }^{14}$ Then, we investigate whether differences in the exchange rate regimes alter our baseline results. In the thirteenth row of Table 3 we present average results from our baseline specification estimated with this extended sample. The importance of the terms of trade in explaining output fluctuations in the extended sample drops slightly as expected (see also results of Schmitt-Grohé and Uribe, 2017). Since averaging out between countries/times with flexible and fixed exchange rate regime can make results more blurry and might bias the real role of news-augmented TOT shocks, we next consider subsamples with fixed versus flexible exchange rate regimes. Following Ilzetzki, Reinhart, and Rogoff (2017), we consider as fixed exchange rate regimes the countries classified as "Pre-Announced Peg" and "Crawling Peg +/- 2\%" in the Coarse Classification. ${ }^{15}$ Results for the two regimes appear in the next two rows of Table 3. Surprisingly, the flexibility of the exchange rate regime does not seem to affect substantially the predictive power of the identified shocks in explaining output or real exchange rate fluctuations. Yet, as expected, news-augmented TOT shocks explain slightly more of the FEV of output and of sovereign spreads for fixed exchange rates, since the flexibility in the exchange rate acts as a shock absorber and hence less variability is associated to CTOT shocks. ${ }^{16}$ Overall, the IRFs, presented in the online appendix, do not differ significantly across the different exchange rate regimes.

\footnotetext{
${ }^{14}$ The countries in our extended sample include Argentina, Brazil, Bulgaria, Chile, Colombia, Ecuador, Mexico, Peru, South Africa, and Turkey. Appendix A contains a detailed explanation of the countries included. Since for some countries in the extended sample we were unable to recover weights for constructing the CTOT index at quarterly frequency and since according to our results for the five LA economies considered using the CTOT or the TOT index in the VAR does not change significantly our results, we use the TOT index instead of the CTOT index in this exercise.

${ }^{15}$ The fixed exchange rate sample is composed by: Bulgaria 2001:Q1-2013:Q4, Ecuador 2000:Q1-2013:Q4, Peru 1997:Q12014:Q2. The flexible exchange rate sample is composed by: Argentina 2002:Q1-2013:Q4, Brazil 1999:Q1-2014:Q3, Chile 1999:Q2-2014:Q2, Colombia 1997:Q1-2014:Q2, Mexico 1994:Q1-2014:Q2, South Africa 1995:Q1-2014:Q2, Turkey 1996:Q3-2014:Q2.

${ }^{16}$ However, in exercises we do not present here for economy of space, we show that when we compute 68 percent credible sets, the FEV for all the variables across both exchange rate regimes are not statistically different .
} 


\subsection{Exogeneity of CTOT Shocks}

For our identification procedure to be valid, CTOT must be exogenous. Clearly, CTOT is largely exogenous from a small open economy's perspective. In our benchmark VAR, following the literature on the identification of TFP news (see, e.g., Barsky and Sims, 2011; Kurmann and Sims, 2017), the news shocks were identified as the linear combination of all other VAR innovations that maximize the forecast error variance of CTOT for a finite horizon. That is, we have used information from domestic variables to identify news-augmented CTOT shocks. If we did so because by placing the CTOT in the external block, we would be missing all the information about expected movements in the CTOT that is contained in the domestic block.

In this subsection, we consider an alternative specification where CTOT and U.S. corporate spread are included in an exogenous block. Thus, we only use information from these two variables to identify the news-augmented CTOT shocks. In particular, we postulate that foreign variables are completely exogenous. Innovations in the world interest rate may affect contemporaneously the CTOT to take into account the phenomenon of financialization of commodity markets (see, e.g., Cheng and Xiong, 2014). Results for this specification are presented in the last row of Table 3. Even if in this case the information set to extract news-augmented CTOT shocks is smaller, the contribution of news-augmented CTOT shocks to explain business cycle fluctuations remains unchanged. ${ }^{17}$ Thus, our conclusions do not depend on this particular specification of the baseline VAR.

\section{Conclusions}

The TOT of many commodity-exporters small open economies are subject to large shocks that can be an important source of macroeconomic fluctuations. The literature, which so far has been based on calibrated business-cycle models, has traditionally suggested this to be the case. In their recent article, Schmitt-Grohé and Uribe (2017) have challenged this view by providing evidence from

\footnotetext{
${ }^{17}$ Although the differences in terms of FEV with respect to the baseline specification are not significant, the two models are not directly comparable due to the imposed block-exogeneity of the CTOT. In particular, in this specification, we are using a smaller information set to extract news about future movements in CTOT, which may induce a bias in the estimation. This is the reason why, in our baseline specification, we use domestic variables to identify news-augmented CTOT shocks.
} 
SVAR that shows that unexpected changes in the TOT account for a small share of output variations in developing countries.

This paper extends the VAR-based analysis of the role of shocks to terms of trade in SchmittGrohé and Uribe (2017) for five Latin American economies using the identification strategy in Kurmann and Sims (2017) that allows to identify news about the terms of trade. Unlike in existing studies (see, e.g., Fernández, González, and Rodríguez (2015); Shousha (2016); Schmitt-Grohé and Uribe (2017); Fernández, Schmitt-Grohé, and Uribe (2017)), where only unanticipated shocks are identified, we recover news-augmented CTOT shocks and show that accounting for news nearly doubles the contribution of CTOT as a source of business cycle fluctuations. News-augmented CTOT shocks explain almost half of output fluctuations in emerging economies. We conclude that the hypothesis about the role of the terms of trade as an important source of cyclical fluctuations in Latin America is, by no means, dead. 
Figure 1: Impulse Responses to a News-Augmented CTOT Shock
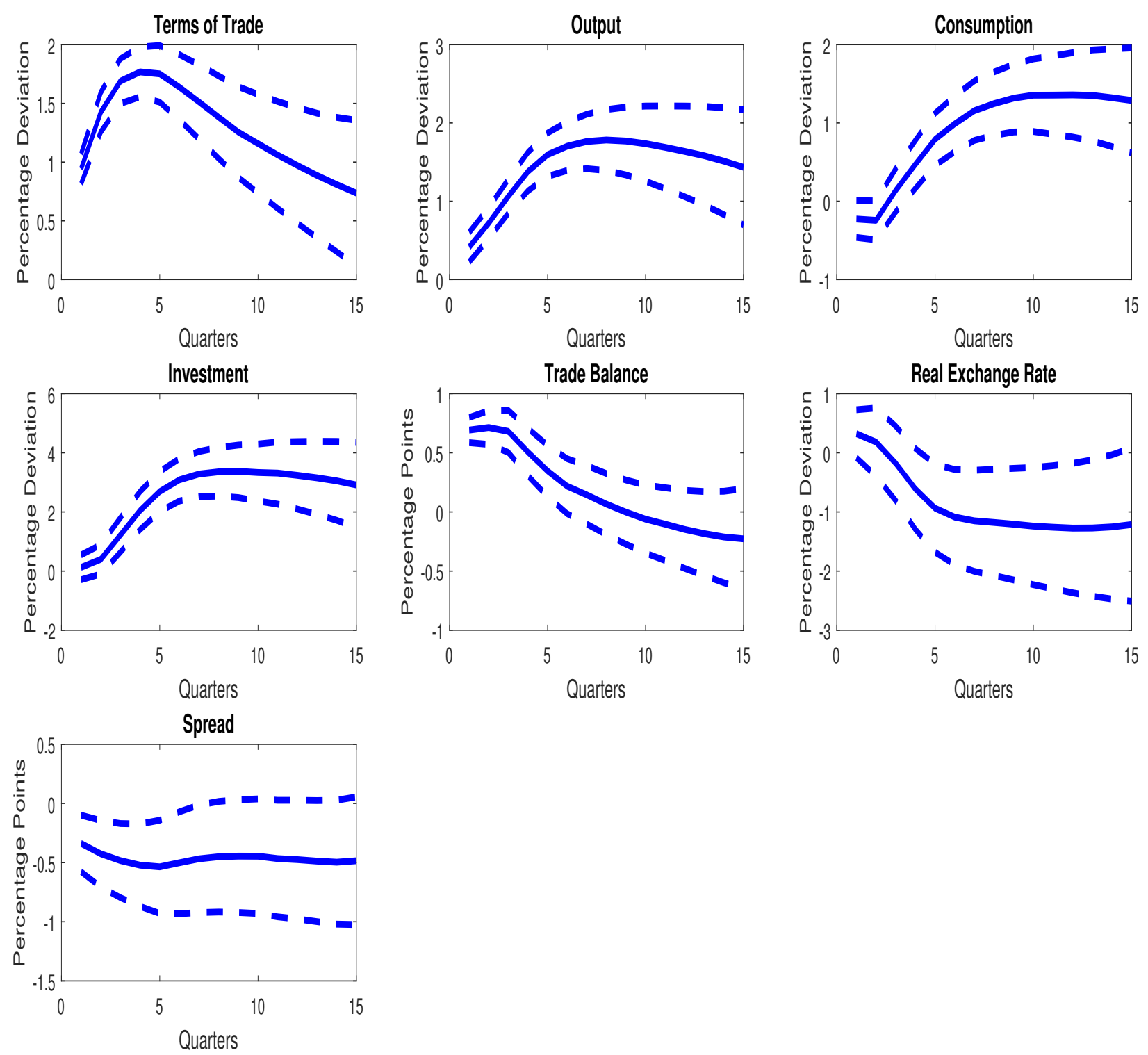

Notes: The solid lines are the average of the country-specific median responses to a one standard deviation newsaugmented CTOT shock. The dashed lines are one standard error bands computed as the square root of the average variance across countries. The underlying country-specific estimates are based on 1000 draws taken from the posterior distribution of the VAR parameters, where the CTOT news shock is identified in accordance with the MFEV estimation procedure described in Section. Horizon is in quarters. 
Table 1: Share of FEV Explained by News-Augmented CTOT Shocks: Country-Level SVAR Evidence

\begin{tabular}{|cccccccc|}
\hline Country & CTOT & GDP & C & I & TB & REER & Spread \\
\hline Argentina & 73 & 35 & 30 & 29 & 10 & 18 & 8 \\
Brazil & 87 & 53 & 36 & 67 & 6 & 46 & 24 \\
Chile & 78 & 51 & 23 & 27 & 52 & 35 & 32 \\
Colombia & 83 & 64 & 40 & 52 & 27 & 18 & 42 \\
Peru & 83 & 44 & 26 & 29 & 65 & 38 & 48 \\
\hline Average & 81 & 49 & 31 & 41 & 32 & 31 & 31 \\
& $(5)$ & $(8)$ & $(7)$ & $(7)$ & $(6)$ & $(7)$ & $(7)$ \\
\hline
\end{tabular}

Notes: This table presents the estimated contribution of the news-augmented CTOT shock to the two-year variation in the variables obtained from each of the 5 country-level VARs. Average estimate is the simple mean of the country specific estimates. Shares are expressed in percent. Standard errors for the average estimates are displayed in parenthesis. Column variables are: Terms of Trade (CTOT), Output (GDP), Consumption (C), Investment (I), Trade Balance to GDP ratio (TB), Real Exchange Rate (REER), and Sovereign Spread (Spread).

Table 2: Share of FEV Explained by Unanticipated CTOT Shocks: Country-Level SVAR Evidence

\begin{tabular}{|cccccccc|}
\hline Country & CTOT & GDP & C & I & TB & REER & Spread \\
\hline Argentina & 60 & 9 & 12 & 6 & 8 & 4 & 4 \\
Brazil & 59 & 27 & 25 & 33 & 9 & 37 & 26 \\
Chile & 34 & 25 & 9 & 17 & 9 & 43 & 16 \\
Colombia & 66 & 37 & 23 & 40 & 13 & 13 & 25 \\
Peru & 44 & 16 & 14 & 16 & 24 & 8 & 26 \\
\hline Average & 53 & 23 & 16 & 22 & 13 & 21 & 19 \\
& $(6)$ & $(6)$ & $(5)$ & $(5)$ & $(4)$ & $(4)$ & $(4)$ \\
\hline
\end{tabular}

Notes: This table presents the estimated contribution of the Cholesky CTOT shock, identified using a Cholesky decomposition where the order of the variables is: [CTOT, BAA, Output, Consumption, Investment, Trade Balance, Real Exchange Rate, Spread], to the two-year variation in the variables obtained from each of the 5 country-level VARs. Average estimate is the simple mean of the country specific estimates. Shares are expressed in percent. Standard errors for the average estimates are displayed in parenthesis. Column variables are: Terms of Trade (CTOT), Output (GDP), Consumption (C), Investment (I), Trade Balance to GDP ratio (TB), Real Exchange Rate (REER), and Sovereign Spread (Spread). 
Figure 2: Impulse Responses to a Cholesky CTOT Shock
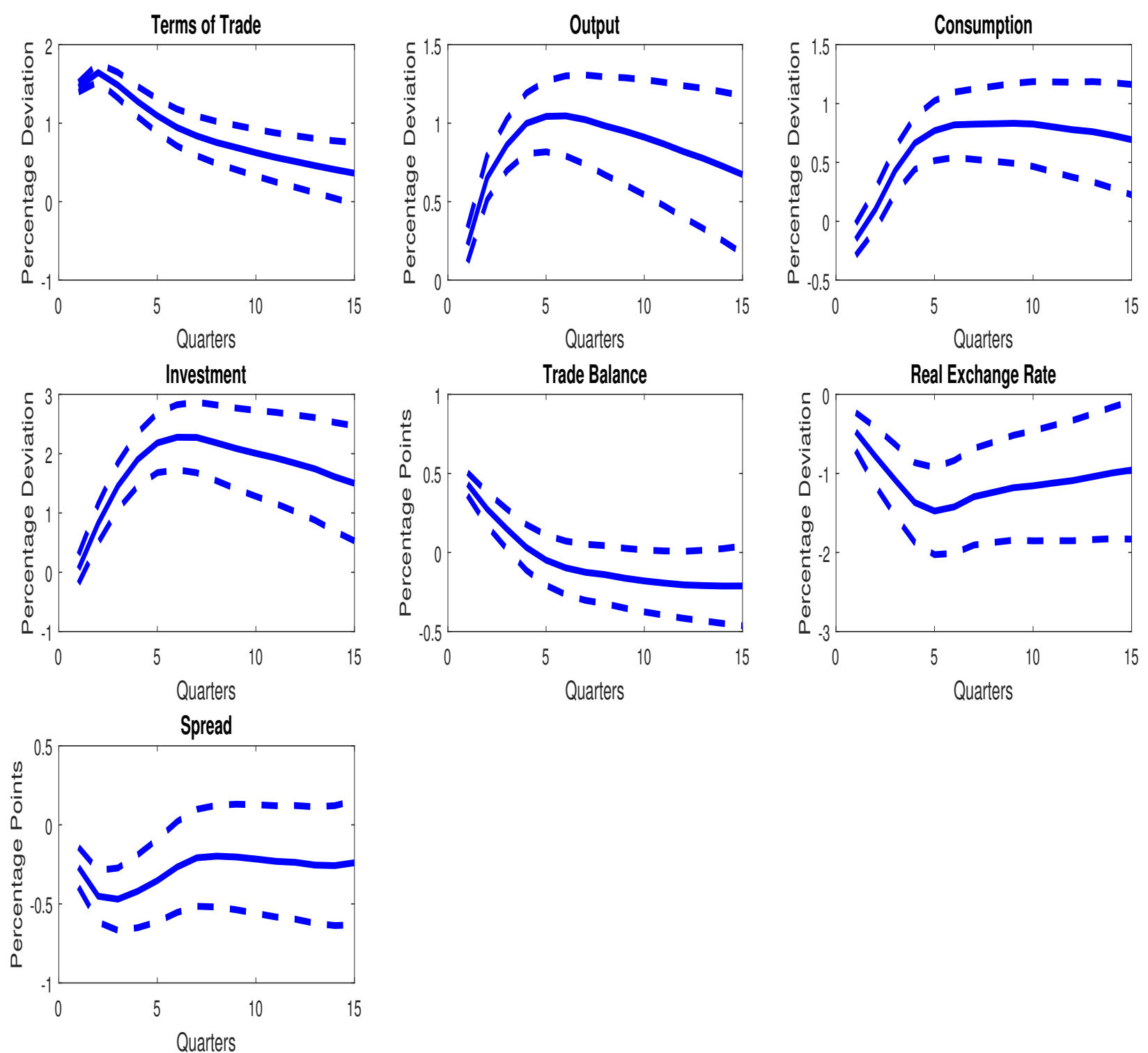

Notes: The solid lines are the average of the country-specific median responses to a one standard deviation Cholesky CTOT shock, identified using the Cholesky decomposition where the order of the variables is: [CTOT, BAA, Output, Consumption, Investment, Trade Balance, Real Exchange Rate, Spread]. The dashed lines are one standard error bands computed as the square root of the average variance across countries. The underlying country-specific estimates are based on 1000 draws taken from the posterior distribution of the VAR parameters, where the unanticipated CTOT shock is identified as the VAR innovation in CTOT using a Cholesky decomposition. Horizon is in quarters. 
Table 3: Share of FEV Explained by News-Augmented CTOT Shocks for Alternative Specifications

\begin{tabular}{|c|c|c|c|c|c|c|c|c|c|c|}
\hline Specification & СТОТ & GDP & $\mathrm{C}$ & I & $\mathrm{TB}$ & REER & Spread & Fut & G & SP \\
\hline Baseline $(\mathrm{H}=5)$ & 81 & 49 & 31 & 41 & 32 & 31 & 22 & & & \\
\hline Baseline $(\mathrm{H}=3)$ & 78 & 43 & 29 & 37 & 29 & 29 & 29 & & & \\
\hline Baseline $(\mathrm{H}=8)$ & 70 & 48 & 27 & 33 & 34 & 30 & 27 & & & \\
\hline G & 78 & 47 & 29 & 40 & 33 & 32 & 30 & & 18 & \\
\hline FFR & 80 & 48 & 32 & 42 & 31 & 30 & 30 & & & \\
\hline Real TBill & 78 & 49 & 32 & 41 & 32 & 27 & 31 & & & \\
\hline CTOT & 83 & 54 & 34 & 43 & 34 & 29 & 31 & & & \\
\hline Stock Prices & 72 & 40 & 26 & 35 & 32 & 28 & 27 & & & 39 \\
\hline CTOT Futures & 76 & 48 & 28 & 40 & 26 & 33 & 26 & 70 & & \\
\hline Baseline with TOT Index & 75 & 32 & 24 & 25 & 38 & 33 & 31 & & & \\
\hline SGU -Annual & 75 & 21 & 16 & 16 & 17 & 17 & & & & \\
\hline SGU (Our Sample) - Annual & 75 & 28 & 12 & 10 & 8 & 12 & & & & \\
\hline 10 countries & 62 & 28 & 22 & 21 & 26 & 26 & 25 & & & \\
\hline Fixed exchange rate regime & 52 & 31 & 26 & 24 & 29 & 20 & 32 & & & \\
\hline Flexible exchange rate regime & 61 & 28 & 19 & 21 & 26 & 27 & 22 & & & \\
\hline Baseline Exo. Block & 99 & 48 & 30 & 42 & 28 & 33 & 36 & & & \\
\hline
\end{tabular}

Notes: This table presents the average estimated contribution of the news-augmented CTOT shock to the two-year variation in the variables. Each row corresponds to an alternative SVAR specification described in Section 4 . Shares are expressed in percent. Column variables are: Terms of Trade (CTOT), Output (GDP), Consumption (C), Investment (I), Trade Balance to GDP ratio (TB), Real Exchange Rate (REER), Sovereign Spreads (Spreads), Commodity Futures (Fut), Government Spending (G), and Stock Prices (SP). Rows specifications are: baseline specification with different truncation horizons, Government Spending (G, Section 4.2), Federal Funds Rate (FFR, Section 4.3), Real TBill Rate (Section 4.3), Stock Prices (Section 4.4), CTOT Futures (Section 4.4), Terms of Trade index (Section 4.5), SGU sample (SGU, Section 4.6), SGU Sample that overlaps with ours (SGU (LA Sample), Section 4.6), extended sample at quarterly frequency (Section 4.7), sample of countries with fixed and flexible exchange rate regimes (Section 4.7) and baseline specification where CTOT and BAA Spread are included in an exogenous block (Baseline Exo. Block, Section 4.8). 


\section{References}

AkINCI, O. (2013): “Global Financial Conditions, Country Spreads and Macroeconomic Fluctuations in Emerging Economies," Journal of International Economics, 91(2), 358-371.

Arezki, R., V. A. Ramey, and L. Sheng (2017): “News Shocks in Open Economies: Evidence from Giant Oil Discoveries," Quarterly Journal of Economics, 132(1), 103-155.

Barsky, R., And E. R. Sims (2011): “News Shocks and Business Cycles," Journal of Monetary Economics, 58(3), 235-249.

Baumeister, C., and L. Kilian (2016): “A General Approach to Recovering Market Expectations from Future Prices with an Application to Crude Oil," Discussion Paper 5782, CESinfo Working Paper Series.

Beaudry, P., and F. Portier (2006): “Stock Prices, News, and Economic Fluctuations," American Economic Review, 96(4), 1293-1307.

Broda, C. (2004): “Terms of Trade and Exchange Rate Regimes in Developing Countries," Journal of International Economics, 63(1), 31-58.

Céspedes, L. F., and A. Velasco (2014): “Was this Time Different?: Fiscal Policy in Commodity Republics," Journal of Development Economics, 106(C), 92-106.

Chen, Y.-C., K. Rogoff, and B. Rossi (2010): “Can Exchange Rates Forecast Commodity Prices?,” Quarterly Journal of Economics, 125(3), 1145-1194.

Cheng, I.-H., And W. Xiong (2014): "Financialization of Commodity Markets," Annual Review of Financial Economics, 6(1), 419-441.

Chinn, M. D., and O. Coibion (2014): “The Predictive Content of Commodity Futures,” Journal of Futures Markets, 34(7), 607-636.

Fernández, A., A. González, and D. Rodríguez (2015): “Sharing a Ride on the Commodities Roller Coaster: Common Factors in Business Cycles of Emerging Economies," Unpublished Manuscript. 
Fernández, A., S. Schmitt-Grohé, and M. Uribe (2017): “World Shocks, World Prices, and Business Cycles: An Empirical Investigation," Journal of International Economics, forthcoming.

Friedman, M. (1953): “The Case for Flexible Exchange Rates," in Essays in Positive Economics, pp. 157-203. University of Chicago Press.

Husain, A. M., and C. Bowman (2004): “Forecasting Commodity Prices: Futures Versus Judgment," IMF Working Papers 04/41, International Monetary Fund.

IlzetzKi, E., C. Reinhart, and K. Rogoff (2017): “Exchange Arrangements Entering the 21st Century: Which Anchor Will Hold?," Discussion Paper 23134, NBER Working Paper.

IlzzetzKi, E., And C. A. Vegh (2008): “Procyclical Fiscal Policy in Developing Countries: Truth or Fiction?," Unpublished Manuscript.

Kaminsky, G. (1990): “Time Varying Risk Premia in Future Markets,” Discussion Paper 90/116, IMF Working Paper Series.

Kilian, L., and B. Hicks (2013): “Did Unexpectedly Strong Economic Growth Cause the Oil Price Shock of 2003-2008?," Journal of Forecasting, 32(5), 385-394.

Kose, M. (2002): “Explaining Business Cycles in Small Open Economies: How Much do World Prices Matter?," Journal of International Economics, 56(2), 299 - 327.

Kurmann, A., and E. Sims (2017): “Revisions in Utilization-Adjusted TFP and Robust Identification of News Shocks," Unpublished manuscript.

MendozA, E. G. (1995): “The Terms of Trade, the Real Exchange Rate, and Economic Fluctuations," International Economic Review, 36(1), 101-37.

PINDYCK, R. (2001): “The dynamics of commodity spot and futures markets: a primer," Energy Journal, 22(3), 1-29.

Roache, S., And N. ERbil (2010): “How Commodity Price Curves and Inventories React to a Short-Run Scarcity Shock," Discussion Paper 222, IMF Working Paper Series. 
Schmitt-Grohé, S., ANd M. Uribe (2017): “How Important Are Terms Of Trade Shocks?,” International Economic Review, forthcoming.

Shousha, S. (2016): "Macroeconomic Effects of Commodity Booms and Busts: The Role of Financial Frictions," Unpublished Manuscript.

Sims, E. R. (2012): “News, Non-Invertibility, and Structural VARs," Advances in Econometrics (fortcoming).

Sinnotr, E. (2009): "Commodity Prices and Fiscal Policy in Latin America and the Caribbean," Unpublished Manuscript.

UhLIG, H. (2003): “What Moves Real GNP?," Unpublished manuscript.

Uribe, M., and V. Z. Yue (2006): “Country Spreads and Emerging Countries: Who Drives Whom?,” Journal of international Economics, 69(1), 6-36. 


\section{A Data Appendix}

We use quarterly data for the following countries and periods: Argentina 1994:Q1-2013:Q3, Brazil 1995:Q1-2014:Q3, Chile 1999:Q2-2014:Q3, Colombia 1997:Q1-2014:Q3, and Peru 1997:Q1-2014:Q3. The sample varies across countries according to data availability. For each case, we use the following series: GDP, Gross Fixed Capital Formation, Private Consumption Expenditure, and Exports and Imports of Goods and Services. All these variables are expressed in current prices and local currency units. We deflate all the variables (except the last two) using the GDP Deflator. The trade balance to GDP ratio is defined as the difference between exports and imports as a share of current GDP. All these series were downloaded from the International Financial Statistics (IFS) database, which is published by the International Monetary Fund. The Real Exchange Rate index is computed by the Bank of International Settlements. This index is defined as geometric weighted averages of bilateral exchange rates adjusted by relative consumer prices. We compute the quarterly average and re-express the series such than an increase (decrease) indicates a depreciation (appreciation). All the series were seasonally adjusted using ARIMA X13. The country spread is proxied by the individual Emerging Markets Bond Index (EMBI) Global (Stripped Spread) computed by JP Morgan, which is a composite of different US dollar-denominated bonds. The Stripped Spread is computed as an arithmetic, market-capitalization-weighted average of bond spreads over US Treasury bonds of comparable duration. Finally, for the international variables, we use the Moody's Seasoned Baa Corporate Bond minus the Federal Funds Rate, available online at FRED under the name BAAFFM, as a proxy for the corporate spread and we compute the Commodity Terms of Trade index for each country following the procedure of Shousha (2016). In particular, we use the IMF Primary Commodity Price data set and the country-specific weights in Table 4, as calculated by Shousha (2016) using annual trade data from UN Comtrade from 1994-2013. The country specific commodity price index is expressed in real terms by dividing it by the U.S. import price of manufactured goods from industrialised countries (source: FRED, code: INDUSMANU).

For the robustness exercises, we use the Export and Import Price index to compute the TOT series for each country. These indexes were downloaded from the national central banks (Brazil, Chile, 
Table 4: Main exported commodities by country-CTOT weights

\begin{tabular}{ll}
\hline Country & Main commodities \\
\hline Argentina & Soybeans (41\%), Crude Oil (12\%), Maize (8.9\%) \\
Brazil & Soybeans (22\%), Iron Ore (17\%), Sugar (9\%) \\
Chile & Copper (72\%), Fish (9\%), Wood (7\%) \\
Colombia & Crude Oil (45\%), Coal (19\%), Coffee $(18 \%)$ \\
Peru & Copper (34\%), Gold (29\%), Zinc $(11 \%)$ \\
\hline
\end{tabular}

Source: Shousha (2016)

Colombia, and Peru) and IMF (Argentina). The country-specific commodity price future index was computed using the average price of the commodity future contracts of the main commodities exported by each country. We employ the same weights as for the commodity based price index, choosing for each good the longest maturity available. In particular, we employ the following contracts: Coffee (6th continuous contract), Cooper, Corn (6th continuous contract), Gold (7th continuous contract), Maize (6h continuous contract), Oil (12th continuous contract), Soybean (8th continuous contract), and Sugar (4th continuous contract). For some commodities (Coal, Fish, Iron Ore, Wood, and Zinc), quotations from future markets are not available for the whole sample. In these cases, we do not consider the good in case it is not representative or we replace it for a similar commodity. The data for commodity prices was downloaded from Quandl. ${ }^{18}$ As a proxy for government expenditure, we use the Government Consumption Expenditure from the IFS database. We deflate this variable using the GDP Deflator. For the robustness exercises, we also use the stock price index for each country. In particular, we use the Merval (Argentina), Bovespa (Brazil), IPGA (Chile), COLCAP (Colombia), and IGBVL (Peru). The historical series were downloaded from Datastream. Finally, the U.S. interest rates are downloaded from the FRED. The Real TBill rate is computed as the quarterly average of the nominal 3 month TBill rate (annualized) minus the U.S. CPI inflation rate over the previous twelve months.

\footnotetext{
${ }^{18}$ https:/ / www.quandl.comprovides continuous series for many commodities based on data from CME.
} 
For the annual specification, we use the same sample of poor and emerging countries and periods as Schmitt-Grohé and Uribe (2017). In particular, the panel contains data for the period 1980 to 2011 for the following countries: Algeria, Argentina, Bolivia, Botswana, Brazil, Burundi, Cameroon, Central African Republic, Colombia, Congo Dem. Rep., Costa Rica, Cote d'Ivoire, Dominican Republic, Egypt Arab Rep., El Salvador, Ghana, Guatemala, Honduras, India, Indonesia, Jordan, Kenya, Korea Rep., Madagascar, Malaysia, Mauritius, Mexico, Morocco, Pakistan, Paraguay, Peru, Philippines, Senegal, South Africa, Sudan, Thailand, Turkey, and Uruguay. The sample used for the specification "SGU (Our Sample) - Annual" includes the following countries: Argentina, Brazil, Colombia, Peru. All the data comes from the World Development Indicators (WDI) database, which is published by the World Bank, and is available online at the Schmitt-Grohe and Uribe (2017) websites. 